University of Nebraska - Lincoln

DigitalCommons@University of Nebraska - Lincoln

Sociology Department, Faculty Publications

Sociology, Department of

$4-2011$

\title{
Understanding how race/ethnicity and gender define age- trajectories of disability: An intersectionality approach
}

\author{
David F. Warner \\ University of Nebraska-Lincoln, dwarner3@unl.edu \\ Tyson H. Brown \\ Vanderbilt University, tyson.brown@vanderbilt.edu
}

Follow this and additional works at: https://digitalcommons.unl.edu/sociologyfacpub

Part of the Demography, Population, and Ecology Commons, Family, Life Course, and Society

Commons, Inequality and Stratification Commons, Medicine and Health Commons, and the Race and

Ethnicity Commons

Warner, David F. and Brown, Tyson H., "Understanding how race/ethnicity and gender define agetrajectories of disability: An intersectionality approach" (2011). Sociology Department, Faculty Publications. 201.

https://digitalcommons.unl.edu/sociologyfacpub/201

This Article is brought to you for free and open access by the Sociology, Department of at DigitalCommons@University of Nebraska - Lincoln. It has been accepted for inclusion in Sociology Department, Faculty Publications by an authorized administrator of DigitalCommons@University of Nebraska - Lincoln. 


\title{
Understanding how race/ethnicity and gender define age-trajectories of disability: An intersectionality approach
}

\author{
David F. Warner ${ }^{1,2}$ and Tyson H. Brown ${ }^{3}$ \\ 1. Department of Sociology, Case Western Reserve University, 10900 Euclid Ave, LC 7124, \\ Cleveland, OH 44106-7124, USA (Corresponding author) \\ 2. Center for Family \& Demographic Research, Bowling Green State University, Bowling Green, OH, USA \\ 3. Department of Sociology, Vanderbilt University, Nashville, TN, USA
}

\begin{abstract}
A number of studies have demonstrated wide disparities in health among racial/ethnic groups and by gender, yet few have examined how race/ethnicity and gender intersect or combine to affect the health of older adults. The tendency of prior research to treat race/ethnicity and gender separately has potentially obscured important differences in how health is produced and maintained, undermining efforts to eliminate health disparities. The current study extends previous research by taking an intersectionality approach (Mullings \& Schulz, 2006), grounded in life course theory, conceptualizing and modeling trajectories of functional limitations as dynamic life course processes that are jointly and simultaneously defined by race/ethnicity and gender. Data from the nationally representative 1994-2006 US Health and Retirement Study and growth curve models are utilized to examine racial/ethnic/gender differences in intra-individual change in functional limitations among White, Black and Mexican American Men and Women, and the extent to which differences in life course capital account for group disparities in initial health status and rates of change with age. Results support an intersectionality approach, with all demographic groups exhibiting worse functional limitation trajectories than White Men. Whereas White Men had the lowest disability levels at baseline, White Women and racial/ethnic minority Men had intermediate disability levels and Black and Hispanic Women had the highest disability levels. These health disparities remained stable with age-except among Black Women who experience a trajectory of accelerated disablement. Dissimilar early life social origins, adult socioeconomic status, marital status, and health behaviors explain the racial/ethnic disparities in functional limitations among Men but only partially explain the disparities among Women. Net of controls for life course capital, Women of all racial/ethnic groups have higher levels of functional limitations relative to White Men and Men of the same race/ethnicity. Findings highlight the utility of an intersectionality approach to understanding health disparities.
\end{abstract}

Keywords: health disparities, functional limitations, race/ethnicity, gender, intersectionality, life course, older adults, USA, disability

\section{Introduction}

Race/ethnicity and gender jointly and simultaneously structure the production and maintenance of health in the United States (Mullings \& Schulz, 2006). ${ }^{1}$ Wide disparities in health exist among older adults (Moen and Spencer, 2006; Williams and Wilson, 2001) and, despite overall improvements in health and targeted policy interventions, there is little evidence of these disparities narrowing over time (Gorman and Read, 2006; Martin et al., 2007). Racial/ethnic minorities have worse health than Whites on a number of indicators including several chronic diseases, functional limitations, and mortality (Hayward \& Heron, 1999; Markides, Rudkin, Angel, \& Espino,
1997; Rogers, Hummer, \& Nam, 2000). Men have higher mortality risks, while Women are more likely to suffer from nonfatal chronic conditions and to be functionally impaired (Gorman and Read, 2006; Laditka and Laditka, 2002).

Notably absent from prior quantitative research, however, is direct examination of how race/ethnicity and gender intersect to define the health of older Americans. An intersectionality approach is centered on structural inequality (Thornton Dill \& Zambrana, 2009) and stipulates that because race/ethnicity and gender are fundamental determinants of opportunity structure, defining access to both the resources that promote health and exposure to the risks that undermine health, their effects cannot be disaggregated or understood separately.

1. It is important to point out here that race/ethnicity and gender are social constructions particular to a given society at a given time (Hirschman, Alba, \& Farley, 2000; Lorber, 1995; Omi \& Winant, 1994). To reflect this social construction we capitalize racial/ethnic/gender groups. 
In short, an intersectionality approach posits race/ethnicity and gender are not separate, additive, dimensions of social stratification but are mutually defining, and reinforce one another in a myriad of ways in the production and maintenance of health across the life course (Mullings \& Schulz, 2006). Prior research applying an intersectionality approach to health has been principally conducted using qualitative, particularly case study and ethnographic, methods (Schulz \& Mullings, 2006). Few quantitative studies have examined racial/ethnic and gender differences in health using such an intersectionality approach (for a recent exception see Read \& Gorman, 2006); fewer still have utilized longitudinal data. Instead, research on health trajectories among older adults has tended to treat race/ethnicity and gender separately, potentially obscuring important differences in how health is produced and maintained, undermining efforts to eliminate health disparities.

Accordingly, the current study examines how race/ethnicity and gender jointly and simultaneously determine age-trajectories of disability among older adults. We use data from the nationally representative 1994-2006 US Health and Retirement Study (HRS) to investigate intra-individual change in functional limitations among White, Black and Mexican American Men and Women, and the extent to which differences in life course capital (O'Rand, 2006) account for initial disparities and rates of change with age between groups. We focus on disability - measured by functional impairments - because it is the manifestation of underlying chronic disease processes ( Kelley-Moore and Ferraro, 2004; Verbrugge and Jette, 1994) and is an important indicator of total morbidity in the population (Hayward \& Warner, 2005).

The current study advances our understanding of health disparities in several ways. First, we employ an intersectionality approach (Mullings \& Schulz, 2006), grounded in life course theory (Elder et al., 2003; O'Rand, 2006), conceptualizing and modeling trajectories of functional limitations as dynamic life course processes jointly and simultaneously defined by race/ethnicity and gender, which provide access to health promoting resources and exposure to health compromising risks over time (Warner \& Hayward, 2006). Second, we model age-based trajectories of functional limitations (Alwin, Hofer, $\&$ McCammon, 2006). Prior studies using wave-based trajectories (e.g., Liang et al., 2008; Mendes de Leon et al., 2005), often in combination with accelerated cohort designs that pool data across multiple birth cohorts (e.g., Kim and Durden, 2007; Kim and Miech, 2009), do not account for age-heterogeneity within survey wave, conflating age and cohort effects, and thus potentially obscuring developmental change in health. Even within prospective cohort studies panel attrition can mask developmental change, which is why we also explicitly model mortal and non-mortal panel attrition in the estimation of agetrajectories of functional limitations. Finally, we advance the study of inequality in health trajectories by examining the experiences of older Mexican American Men and Women, an important group given their projected increase as a share of the US aged population (Angel \& Whitfield, 2007). Prior studies of health trajectories have largely focused on Black-White differences (e.g., Ferraro and Farmer, 1996b; Kelley-Moore and Ferraro, 2004; Taylor, 2008) or considered only an amorphous Hispanic category (e.g., Liang et al., 2008).

\section{Prior studies}

\section{Racial/ethnic and gender disparities in health}

Race/ethnicity and gender are key dimensions of social stratification. As such, racial/ethnic/gender-stratified opportunity structures result in the accumulation of disadvantages for Women and racial/ethnic minorities and consequently disparate aging experiences (Bird \& Rieker, 1999; Moen and Spencer, 2006; Mullings and Schulz, 2006). Racial/ethnic disparities in health are well-documented (Angel and Whitfield, 2007; Verbrugge, 1989; Williams and Collins, 1995). On average, Blacks have a higher prevalence of several chronic diseases (Blackwell, Collins, \& Coles, 2002), higher rates of disability and levels of functional impairment (Fuller-Thomson et al., 2009; Kelley-Moore and Ferraro, 2004; Kelley-Moore and Ferraro, 2005), and experience higher mortality rates than do Whites (Rogers et al., 2000). Similarly, various Hispanic subgroups exhibit higher rates of several chronic diseases (Markides, Coreil, \& Rogers, 1989) and have worse functional health than Whites (Markides, Eschbach, Ray, \& Peek, 2007). However, older Hispanics-particularly Mexican Americans - have all-cause mortality rates similar to Whites (Hummer, Rogers, Amir, Forbes, \& Frisbie, 2000), part of the Hispanic epidemiological paradox. As a result of high morbidity rates coupled with low mortality rates, Mexican Americans can expect to live more years disabled than Whites or Blacks (Hayward, Warner, \& Crimmins, 2007).

Gender disparities in health are also well-known: Women live longer than Men, on average, but are more likely to suffer from chronic health problems and have multiple comorbidities (Laditka and Laditka, 2002; Newman and Brach, 2001; Verbrugge, 1989). However, the magnitude of the gender gap in health varies considerably depending on the morbidity measure (Gorman and Read, 2006; Macintyre et al., 1996). Nevertheless, prior studies consistently find that Women are more likely to have functional limitations and live more years disabled (Laditka and Laditka, 2002; Read and Gorman, 2006).

Prior quantitative studies rarely consider how race/ethnicity and gender jointly differentiate the health status of older adults, instead examining race/ethnicity or gender as if they were separate dimensions of social stratification. By contrast, an intersectionality approach systematically examines the joint and simultaneous influences of race/ethnicity and gender on health and health trajectories across the life course (Mullings \& Schulz, 2006). An intersectionality approach to health is distinct from other approaches, such as the multiple-hierarchy stratification perspective (Clark \& Maddox, 1992), which asserts that race/ethnicity and gender are "independent but potentially interactive influences on changes in functional status overtime (p. S223, emphasis added), or notions of double- or triple-jeopardy (Ferraro \& Farmer, 1996a), which assume that racial/ethnic and gender advantages or disadvantages simply accumulate in an additive fashion. These other approaches reify notions of race/ethnicity and gender as separate (Thornton Dill \& Zambrana, 2009). An intersectionality approach begins with the premise that forms of oppression (e.g., racism, sexism) overlap, defining unique social groups, and thus posits that the consequences of race/ethnicity and gender cannot be understood sufficiently by studying these phenomena separately; rather, understanding their overall effects necessitates examining how race/ethnicity/gender structurally interrelate, overlap or intersect to establish access to resources (both material and relational) that promote and exposures to the risks that undermine health across the life course.

Although few quantitative studies have examined racial/ ethnic/gender disparities in health using an intersectionality approach, there are empirical indications that gender conditions health among racial/ethnic minorities. Black and Hispanic Women have higher prevalence rates of several chronic conditions than Whites, with Black Women the most disadvantaged (Greenlund et al., 1998; Hayward et al., 2000; McGee et al., 1996). Racial/ethnic minority Women also have disproportionately high levels of functional limitations compared to 
White Women. Moreover, the gender gap in disability among racial/ethnic minorities is greater than that among Whites (Hayward and Heron, 1999; Hayward et al., 2007; Read and Gorman, 2006). Prior studies have often found that Black Women have health profiles and experiences distinct from other racial/ethnic/gender groups, undergoing accelerated physiological decline beginning in the reproductive years $-\mathrm{a}$ phenomenon Geronimus (2001) termed "weathering." For example, Black Women in midlife have higher levels of the underlying physiological indicators of many chronic conditions (Geronimus, Hicken, Keene, \& Bound, 2006) and are more likely to be hospitalized (Ferraro, Thorpe, McCabe, KelleyMoore, \& Jiang, 2006).

\section{Race/ethnicity/gender disparities in disability trajectories}

Prior studies of racial/ethnic and gender disparities in health and disability, as described above, have typically examined between-person differences. In contrast, developmental life course research aims to explain long-term, intra-individual patterns of stability and change. Whereas a between-person design is useful for investigating group differences in health and functional status, it provides very little information on the timing, pace, and development of health. The within-person approach of developmental life course theory focuses on patterns or trajectories of intra-individual health change with age (Alwin et al., 2006; George, 2009). Notably, the current study integrates the demographic and developmental perspectives by using both between- and within-person approaches to investigate how age-trajectories of functional impairment vary across racial/ethnic/gender groups among U.S. older adults.

It is widely recognized that health develops across the life course and disparities in health trajectories exist between social groups (House et al., 1994; Kuh and Ben-Shlomo, 1997). Still, how these trajectories change with age is a matter of considerable theoretical and empirical debate, as three competing hypotheses have emerged to explain inequality with age (see Ferraro \& Farmer, 1996b). The aging-as-leveler hypothesis posits that because aging involves negative health consequences for both advantaged and disadvantaged populations, those with health advantages earlier in life have the most to lose in terms of health decline. Therefore, group differences in populationaverage trajectories functional impairment would be expected narrow or converge with age. The persistent inequality hypothesis asserts that demographic and socioeconomic factors have consistent effects on health with age so racial/ethnic/gender differences in disability would be expected to remain stable with age, as demonstrated by parallel population-average age-trajectories. Alternatively, the cumulative advantage/disadvantage hypothesis (Dannefer, 1987) argues that inequality increases as the cohort ages because individuals with an initial advantage have increasing access to resources and exposure to opportunities with age, while those with initial disadvantages have diminished access to resources and greater exposure to risk with age ( $\mathrm{O}^{\prime}$ Rand, 2006). Thus, were this the case, racial/ ethnic/gender disparities in disability should increase with age as population-average trajectories diverge.

The nature of racial/ethnic/gender disparities in disability trajectories is unclear from prior research, as few have applied an intersectionality approach. Many prior longitudinal studies of racial/ethnic disparities in health, disability and mortality have not been primarily concerned with how gender conditions disability trajectories (Kahng et al., 2004; Liang et al., 2008; but see Mendes de Leon et al., 2005). Instead, research on disability trajectories has largely focused on BlackWhite differences (Ferraro and Farmer, 1996b; Kelley-Moore and Ferraro, 2004; Kim and Miech, 2009; Taylor, 2008) controlling for gender, or gender differences controlling for race/ethnicity (Anderson et al., 1998; Guralnik and Kaplan, 1989; Kahng et al., 2004). Such studies largely demonstrate that Black-White disparities in disability are exacerbated over time as trajectories of functional impairment diverge with age (Kelley-Moore and Ferraro, 2004; Kim and Durden, 2007; Liang et al., 2008; Mendes de Leon et al., 2005), although there is some competing evidence of persistent inequality between Blacks and Whites (Ferraro and Farmer, 1996b; Kelley-Moore and Ferraro, 2004) or convergence between Blacks and Whites at the oldest ages (Kim \& Miech, 2009). The disability trajectories of Mexican Americans vis-à-vis Blacks and Whites have not been well-documented. Liang et al. (2008) found that, while they had higher initial levels of ADL and IADL impairment, Hispanic older adults did not differ from Non-Hispanic Whites in terms of change in impairment with time. Unfortunately, Liang et al. (2008) used the amorphous Hispanic group in their analysis, combining a number of distinct subgroups, and thus obscuring important variations (see Markides et al., 2007; Read and Gorman, 2006).

Despite the fact that on average Women have higher disability prevalence rates than Men (Gorman and Read, 2006; Laditka and Laditka, 2002), gender differences in age-trajectories of disability are ambiguous. Several studies suggest that Men and Women have similar average rates of change in functional status (e.g., Guralnik and Kaplan, 1989; Kahng et al., 2004). However, other wave-based studies suggest that Women face accelerated rates of disability and functional impairment (e.g., Anderson et al., 1998; Liang et al., 2008), consistent with cumulative advantage/disadvantage hypothesis. Yet, still several studies find that while Women have higher initial levels of functional impairment, Men experience higher rates of functional decline, resulting in a convergence of the disability gender gap (e.g., Maddox and Clark, 1992; Mendes de Leon et al., 2005).

While prior studies have infrequently taken an intersectionality approach to understand cross-sectional differences in the prevalence of disability across racial/ethnic/gender groups, longitudinal investigations have been even rarer. The few longitudinal studies that exist find that Black Women overall have disproportionately higher levels of functional impairment and steeper rates of increase with age than do Black Men, compared to the average differences between White Women and Men (Kim and Miech, 2009; Mendes de Leon et al., 2005). How the average functional trajectories of older Mexican American Women compare to older Mexican American Men, Blacks, and Whites is unknown. Yet, there is some evidence to suggest that Hispanic Women generally face elevated risks of work-disability similar to those experienced by Black Women (Brown \& Warner, 2008).

\section{Socioeconomic explanations for disparities in disability trajectories}

Although an intersectionality approach to health has often emphasized the joint and simultaneous production by race/ethnicity, gender, and class (Schulz \& Mullings, 2006), a life course perspective on health conceptualizes social class as resources promoting health and risks undermining health and thus that health is shaped over time by the various forms of life course capital allocated according to racial/ethnic/gendered opportunity structures ( Kuh and Ben-Shlomo, 1997; O'Rand, 2006). An extensive body of research has documented the health consequences of numerous forms of life course capital-material, relational, and lifestyle - including childhood socioeconomic conditions ( Haas, 2008; Warner and Hayward, 2006), educational attainment ( Dupre, 2007; Hayward et al., 2007), income (Rogers et al., 2000), wealth (Smith, 1999), marriage (Waite, 1995), and health-related lifestyle behaviors (Mulatu \& Schooler, 2002). Thus, bringing together life course and intersectional- 
ity perspectives, we posit that social class, broadly defined, reflects resources promoting health and risks undermining health (O'Rand, 2006) that are borne out of racial/ethnic/gendered opportunity structures and thus which links race/ethnicity/ gender to later-life health. That is, given that Black and Mexican American Americans are on average disadvantaged relative to Whites on these key social class determinants of health, and that Women are disadvantaged relative to Men on many (though not all) of these same indicators, we would expect that the socioeconomic inequality experienced by racial/ethnic/gender minorities would explain racial/ethnic/gender disparities in levels and rates of change because health trajectories are influenced by the accumulation of resources and risks over time ( Mullings and Schulz, 2006; O'Rand, 2006). ${ }^{2}$

Overall, previous research suggests that racial/ethnic socioeconomic inequality accounts for much-but not all-of racial/ethnic disparities in health and functional impairment (Fuller-Thomson et al., 2009; Hayward et al., 2000; Kim and Miech, 2009; Warner and Hayward, 2006). For example, in a study of North Carolina elders aged 65 and over, adjusting for SES, morbidity, and social support eliminated the diverging trajectories of Blacks and Whites, though a consistent gap remained (Kelley-Moore \& Ferraro, 2004). While prior studies have not examined trajectories of disability among Hispanics, in their cross-sectional study, Read and Gorman (2006) found that adjusting for SES (incl. marital status) not only eliminated the disadvantage faced by Mexican American Women, but actually reversed it so that Mexican American Women had a lower odds of functional limitations than White Men. Consistent with an intersectionality approach, some prior studies suggest that SES better explains racial/ethnic differences in functional limitations among Men than among Women (Mendes de Leon et al., 2005; Read and Gorman, 2006). By and large, though, the explanatory power of SES disparities in understanding functional limitations defined by race/ethnicity/ gender has not been fully documented.

\section{Research questions}

Two broad sets of questions remain about disparities in disability trajectories among older adults: (1) How do population-average age-trajectories of functional impairment vary between White, Black and Mexican American Men and Women? Does the pattern of change between groups show divergence (i.e., cumulative disadvantage), remain stable (i.e., persistent inequality), or narrow (i.e., aging-as-leveler) with age? Are these disparities consistent within and between racial/ethnic and gender groups? (2) Are these population-average patterns of disability inequality explained by racial/ethnic/gender differences in childhood and adult socioeconomic status and health behaviors? Is the explanatory power of these factors similar for all race/ethnicity/gender groups? We provide answers to both sets of questions in the current study.

\section{Data and methods}

We used seven waves of panel data from the 1994-2006 US Health and Retirement Study (HRS) to examine how race/ethnicity and gender intersect to define trajectories of disability. The HRS is a nationally representative panel of non-institutionalized adults born between 1931 and 1941 (inclusive) first interviewed in 1992 and contains oversamples of African-Americans and Hispanics. While a small proportion of the population is institutionalized at the target ages of the panel, levels of functional impairment may be somewhat understated given the ex- clusion of institutionalized persons at baseline (HRS, 2006). Respondents have been reinterviewed biennially. We excluded the initial 1992 interview from the analysis because the measures of functional limitations at that interview differ from those asked thereafter (see also Haas, 2008). The 1994-2006 panel covers respondents approximately ages 53 to 75 .

We limited our analytic sample to 8701 self-identified White, Black, and Mexican Americans. We examined Hispanic respondents only of Mexican-origin because the HRS oversampling procedures principally increased their inclusion and other Hispanic subgroups (e.g., Puerto Ricans, Cubans) were sampled with frequencies too small to permit multivariate estimation (see HRS, 2006). Given subgroup heterogeneity (Hummer et al., 2000; Read and Gorman, 2006), it made little sense to retain these Hispanic respondents as a residual group. We also excluded respondents from other racial groups due to small sample sizes.

\section{Measures}

\section{Dependent variable}

Disability was measured with twelve standard self-reported items assessing mobility, strength, and upper- and lower-body Functional Limitations. Respondents were asked whether "because of a health or physical problem" they had difficulty: walking several blocks; walking one block; walking across the room; climbing several flights of stairs; climbing a single flight of stairs; sitting for two hours; getting up from the seated position; stooping, kneeling, or crouching; pushing or pulling large objects; lifting ten pounds; raising arms above the shoulder; or picking a dime off of a table. As respondents were to exclude any difficulties they expected to last less than three months, these items likely reflect the consequences of chronic disease processes (Verbrugge \& Jette, 1994). Given inconsistency in response categories across waves, we dichotomized each measure ( 1 = any difficulty) and created a summary count of limitations with a theoretical range of $0-12$ (observed range was $0-10$; KR20 $=0.84-0.86$, depending on wave [not shown]). While prior studies of disability have often used measures of basic (ADL) and instrumental (IADL) activities of daily living, these tend to measure much more severe forms of impairment (e.g., difficulty bathing) rare among the young-old population represented in the HRS (Haas, 2008).

\section{Independent variables}

Consistent with an intersectionality approach (see Read \& Gorman, 2006), our primary independent variable measures the nexus of self-reported race/ethnicity and gender, coded as a series of mutually-exclusive dummy variables for White Women, Black Men, Black Women, Mexican American Men, and Mexican American Women. Combining self-reported race/ethnicity and gender in this way allows us to contrast the disability trajectories of each racial/ethnic/gender group against the experiences of White Men (the reference category), the group that occupies the most privileged position in the opportunity structure. We classified respondents as Mexican-origin if the reported that they considered themselves to be "Hispanic or Latino" and then indicated that they were "Mexican American" or "Chicano" on a follow-up question concerning detailed Hispanic ethnicity. We coded respondents White or Black if they indicated that they considered themselves, respectively, as "primarily [W] hite or Caucasian" or "Black or African American" and did not report any Hispanic ethnicity.

To capture developmental change in functional impairment (Singer \& Willett, 2003), we specified both a linear age parame-

2. Although prior quantitative studies of health have examined racial/gender/social class intersectionality, our preliminary analyses (described below) did not detect any systematic differences in the effects of socioeconomic indicators across racial/ethnic/gender groups consistent with the theoretical propositions described here. 
ter and a non-linear $a g e^{2}$ parameter. Exact age was centered at 53 , the lowest observed whole age, to facilitate interpretation (i.e., at 53 , age $=0$ ) with a range of -0.58 to 22.75 . Past research has found the age-related change in disability to be non-linear necessitating both parameters ( Kim and Durden, 2007; Kim and Miech, 2009; Mendes de Leon et al., 2005).

\section{Covariates}

We include a number of life course factors capturing the differential health risks faced by racial/ethnic/gender groups. These covariates include measures of early life social origins, adults SES, marriage, and health-related behaviors, and controls for nativity and panel attrition.

Early life social origins - We measured early life social origins with three dummy variables indicating whether the Family was Poor (=1), Father's Education, and Mother's Education (at least a high school diploma $=1$; otherwise $=0$ ). A number of respondents were missing on these measures because they either did not know or because they attrited from the panel prior to 1998 when family of origin income status was first asked. To retain these cases in the analysis, we also specified a dummy variable for missingness on each variable (missing $=1$; otherwise $=0$ ).

Adult socioeconomic status - Five measures capture respondents' adult SES. Education was operationalized as total years of schooling, ranging from 0 to 17 or more. Categorical indicators of education did not fit the data as well as the interval specification (preliminary analyses not shown). Earnings is the sum of all wages and salaries. Social Security Income is the value of all Social Security payments received. Net Worth is the sum of all household assets, minus any debts. As earnings, Social Security Income, and net worth were measured at the household-level, we created income and wealth equivalencies across households by dividing each measure by the square-root of household size ( Azpitarte, 2010; Brady, 2009) and logarithmically transformed each income and wealth measure to adjust for left skewness. To facilitate interpretation in our growthcurve models (Singer \& Willett, 2003), described below, we centered education so that zero indicates 12 years of schooling (i.e., completion of high school), and grand mean centered the income and wealth measures so that zero indicated the average value on each measure. In the Labor Force is a dummy variable coded one if the respondent indicated working for pay or otherwise was in the labor force. We captured Health Insurance availability with a dummy variable coded one if the respondent had health insurance coverage from any source.

Marriage - We specified marital status with a series of dummy variables for Divorced $(=1)$, Widowed $(=1)$, or Never Married (=1). Married served as the reference category.

Health-related behaviors - Several dummy variables summarized known behavioral risks of poor health and disability. Obesity was measured with a dummy variable coded one if the respondent had a BMI above 30. Two dummy variables capture smoking behavior: whether the respondent Ever Smoked $(=1)$ and Currently Smokes (=1). We measured alcohol use with a dummy variable for Heavy Drinking $(3+$ drinks $/$ day $=1)$. Due to measurement inconsistencies across waves we were unable to construct a sex-specific measure of heavy drinking.

Nativity - Given the well-documented immigrant health advantage (Hummer et al., 1999; Palloni and Arias, 2004; Rogers et al., 2000), we controlled for the nativity of respondents with a dummy variable coded one if the respondent was an Immigrant.
Panel attrition - With any longitudinal panel, nonrandom mortal and non-mortal panel attrition is of concern as both may be related to observed health disparities (Dupre, 2007; Kim and Miech, 2009; Liang et al., 2008). Over the survey period, $22.5 \%$ of the sample (1955 cases) missed at least one interview for reasons other than death and $14.5 \%$ of the sample (1263 cases) died. As is evident from Table 1, the number of waves respondents were interviewed and the likelihood of dying during the observation period varied by race/ethnicity/gender. Preliminary analyses (not shown) revealed that mortal attrition was significantly associated with higher levels of functional limitations, while non-mortal attrition (drop out) was significantly associated with fewer limitations. To account for racial/ethnic/gender differences in panel attrition, we included two additional control variables in our models (see Liang et al., 2008 for a similar approach). We captured the number of waves a respondent was observed with count of Occasions ranging from 1 to 7 (centered at 1) and included a dummy variable indicating whether the respondent was observed to have Died $(=1)$ during the panel. Preliminary analyses (not shown) revealed this approach yielded results similar to those including two corrections for attrition and mortality based on the two-stage Heckman (1979) estimator (see Ferraro \& Kelley-Moore, 2003).

Race/ethnicity/gender, early life social origins, nativity, and the attrition indicators were time-invariant, while the adult SES, marriage, and health behavior covariates were time-varying and measured contemporaneously. This strategy is consistent with the focus of our analysis to document population-average racial/ethnic/gender trajectories of disability and the extent to which differences between groups were mediated by life course inequalities. We chose not to lag covariates, so that functional limitations are predicted by covariates measured at the previous interview, because this reduced the cases available for analysis by slightly more than $16 \%$, diminishing statistical power. Supplemental analyses (not shown) indicted that the findings presented here were largely similar to those with the covariates lagged.

\section{Analytic strategy}

Consistent with developmental and life course theory (Alwin et al., 2006), we estimated age-based trajectories to examine age-associated changes in functional impairment accurately (Singer \& Willett, 2003). We modeled random coefficient growth curves within a linear mixed model (i.e., multilevel) framework. These models are well-suited for the assessment of individual change with age (Raudenbush and Bryk, 2002; Singer and Willett, 2003). Growth curve models estimate individual trajectories based on person-specific initial values of functional limitations (intercepts) and rates of change (slopes) that describe intra-individual patterns of change in functional impairment as a function of age. These models have been used in a number of prior studies on racial/ethnic differences in health trajectories (e.g. Haas, 2008; Herd, 2006; Kelley-Moore and Ferraro, 2004; Liang et al., 2008; Shuey and Willson, 2008).

We used SAS ${ }^{\circledR}$ PROC MIXED to estimate linear mixed models of intra-individual change in functional imitations with age using maximum likelihood (ML). Although the Gaussian distributional assumption was violated due to the slightly skewed distribution of functional limitations $($ skew $=1.01)$, preliminary analyses with a logarithmically transformed outcome, as well as specifying a Poisson distribution for the count of limitations, produced comparable results, suggesting that the findings were not sensitive to the normality assumption.

ML estimation has the advantage of being able to incorporate all respondents observed at least once. Under maximum likelihood estimation, Raudenbush and Bryk (2002, p. 199- 
Table 1. Means (Standard Deviations) for Baseline (1994) Study Variables by Race/Ethnicity/Gender $(N=8701)$ a,b

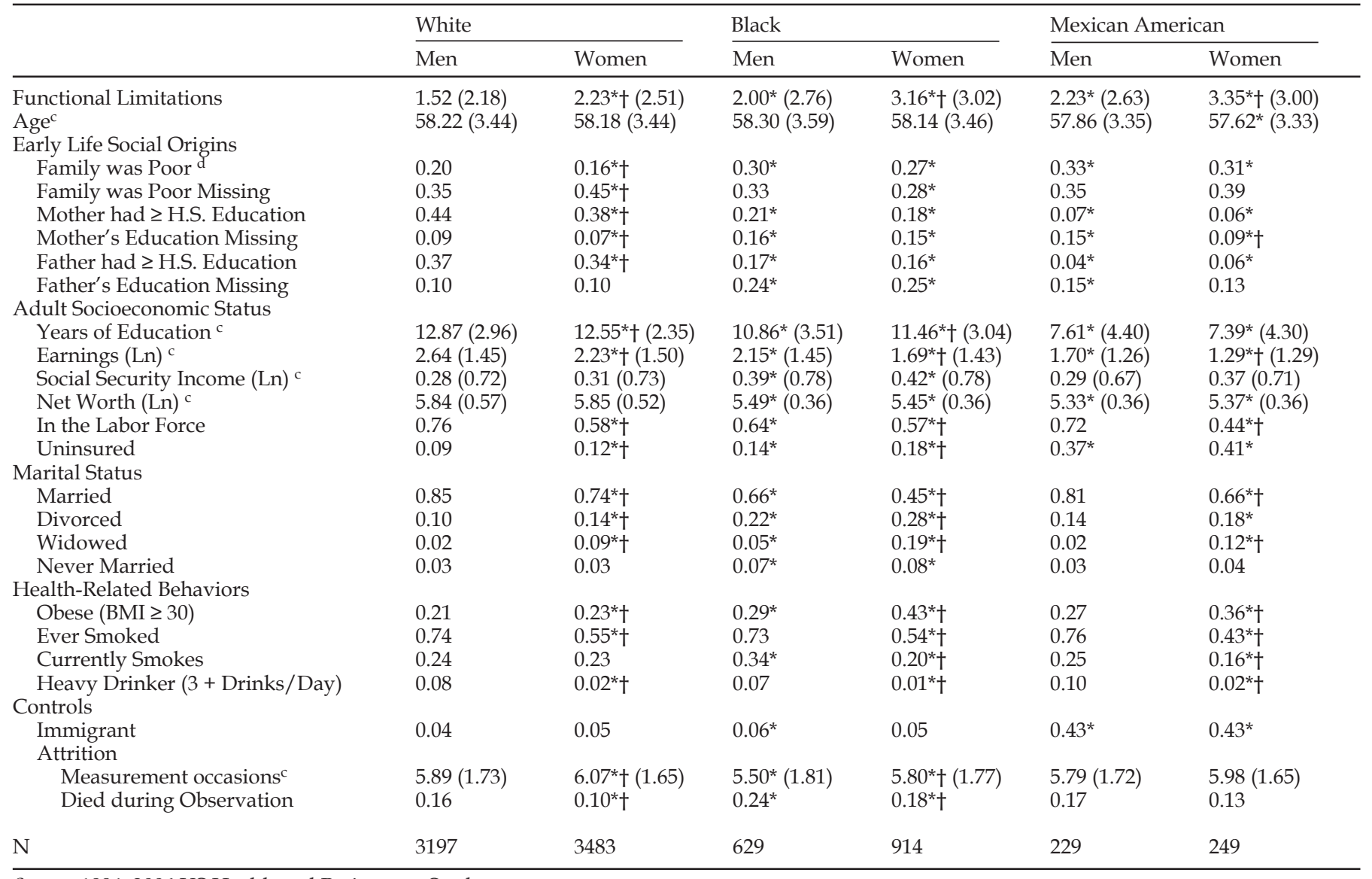

Source: 1994-2006 US Health and Retirement Study.

a. Means for dummy variables can be interpreted as the proportion of the sample coded 1 on that indicator.

b. Welch-Satterthwaite T-Tests computed for difference in means with unequal variances; Statistically significant differences $(p<0.05)$ between racial/ethnic/gender group and White Men are denoted by an *; Statistically significant differences $(p<0.05)$ between Men and Women with ra$\mathrm{cial} / \mathrm{ethnic}$ groups are denoted by a $\dagger$

c. Mean value for original, non-centered, variable.

d. Variable was measured in 1998.

200) note that with attrition: (1) the data may be assumed to be missing at random (MAR), meaning that the probability of missing a time point is independent given the observed data, and (2) this is a reasonable assumption when the observed data include confounding variables related to both attrition and the dependent variable. In this study, we control for attrition by including indicators for whether individuals dropped out of the panel. These indicators capture any additional individual characteristics associated with non-mortal (occasions) and mortal (died) attrition unaccounted for by covariates already in the model and thus satisfy the conditions necessary to treat the missing data mechanism as ignorable (see also Little \& Rubin, 1987). Assuming the data are MAR, because all of the data were used in the analysis and a fully efficient estimation procedure (ML) was utilized, the model estimates are asymptotically unbiased. This approach is consistent with recent studies on disparities in health trajectories (e.g., Haas, 2008; Herd, 2006; Liang et al., 2008; Shuey and Willson, 2008; Willson et al., 2007).

We conducted preliminary analyses to determine the specification of fixed and random effects for change in functional limitations with age (results not shown). An empty (random intercept only) model revealed an interclass correlation of 0.705 , indicating that $70.5 \%$ of the variance in functional limitations was between-persons, over time. Comparisons of model fit between models of increasing complexity indicated that a random quadratic model provided the best fit for describing the age-related change in functional limitations. It was this unconditional model-containing only specification of fixed and random effects for age - to which we added parameters for race/ethnicity/gender.

Following Singer and Willett (2003), the level 1 or repeated observations equation that captured change in functional limitations associated with age was as follows:

$$
Y_{\mathrm{ij}}=\pi_{0 i}+\pi_{1 i} \mathrm{Age}_{i j}+\pi_{2 i} \mathrm{Age}_{i j}^{2}+\varepsilon_{i j}
$$

where $Y_{\mathrm{ij}}$ represents the functional impairment for individual $i$ at occasion $j, \pi_{0 i}$ represents the mean number of functional limitations at age 53 for individual i, $\pi_{1 i}$ represents the mean linear rate of change at age 53 and $\pi_{2 i}$ is a quadratic slope representing the average acceleration in the linear rate of change in number of functional limitations for individual $i$ with each additional year of age, and $\varepsilon_{i j}$ is an error term representing the deviation of each individual $i$ at occasion $j$ from their average level of impairment.

The level 2 or person-level equations captured race/ethnicity/gender differences in the initial level of functional limitations, with adjustments for nativity and panel attrition, and differences in the rates of change in functional limitations by including these as predictors of the level 1 parameters as follows: 


$$
\begin{aligned}
\pi_{0 i}= & \gamma_{00}+\gamma_{01} \text { Race } / \text { Ethnicity } / \text { Gender }+\gamma_{02} \text { Immigrant } \\
& +\gamma_{03} \text { Occasions }+\gamma_{04} \text { Died }+s_{0 i} \\
\pi_{1 i}= & \gamma_{10}+\gamma_{11} \text { Race } / \text { Ethnicity/Gender }+s_{1 i} \\
\pi_{2 i}= & \gamma_{20}+\gamma_{21} \text { Race/Ethnicity/Gender }+s_{2 i}
\end{aligned}
$$

where the initial level of functional limitations for individual $i\left(\pi_{0 i}\right)$ is the product of an intercept $\gamma_{00}$, which represents the population-level average level of functional limitations, a vector of parameters $\gamma_{01}$ corresponding to differences in the average level of functional limitations for each of the five racial/ ethnic/gender groups (White Men is the reference), with adjustments for nativity $\left(\gamma_{02}\right)$, the number of occasions individual $i$ was observed $\left(\gamma_{03}\right)$, and whether individual $i$ died during the observation period $\left(\gamma_{04}\right)$, and a random error term $S_{0 i}$ for individual $i$ 's deviation from the average level of limitations; the linear and quadratic rates of change in functional limitations for individual $i$ ( $\pi_{1 i}$ and $\pi_{2 i}$, respectively) are a product of intercepts corresponding to the average rate of change $\left(\gamma_{10}\right.$, $\left.r_{20}\right)$, vectors of parameters $\left(\gamma_{11}, \gamma_{21}\right)$ for each of the five dummy variables for race/ethnicity/gender corresponding to racial/ ethnic/gender group deviations from the average rates of linear and quadratic change (where White Men is the reference), and random error terms $\left(s_{1 i}, S_{2 i}\right)$ for the deviation of individual $i$ from the average rates of linear and quadratic change.

To test whether early life social orgins, contemporaneous socioeconomic status, marital status, and health behaviors explained race/ethnicity/gender differences in the level and rate of change in functional limitations, subsequent models introduced these covariates to each growth parameter. Preliminary analyses (not shown) revealed that these covariates were, for the most part, not significantly associated with the linear $\left(\pi_{1 i}\right)$ and quadratic $\left(\pi_{2 i}\right)$ growth terms and explained less than $1 \%$ of the variance in the slopes. Accordingly, the models presented here only account for the effect of these covariates on the intercepts $\left(\pi_{0 i}\right)$.

While prior quantitative studies of health have examined racial/social class or racial/gender/social class intersectionality (e.g., Farmer and Ferraro, 2005; Fuller-Thomson et al., 2009), these studies have focused on a limited number of social class indicators, such as income or education. However, in the present study, we used 15 measures of social class and it was not possible to model such intersections using the approach of these prior studies. In preliminary analyses we tested whether the effects of our early life and adult socioeconomic indicators differed across groups by estimating race/ ethnicity/gender stratified models. The findings from these models generally did not reveal any systematic differences in the effects (see also Warner \& Hayward, 2006). One notable exception was the effect of being in the labor forcewhere Black Men, Black Women, Mexican American Men, and Mexican American Women in the labor force had significantly fewer functional limitations than White Men or White Women in the labor force (results not shown). This finding reflects the fact that racial/ethnic minority Men and Women are less apt to work in white-collar occupations that can accommodate mild forms of functional impairment and are more likely to become work-disabled (Brown and Warner, 2007; Hayward et al., 1996). Nevertheless, the general absence of systematic differences in effects across racial/ethnic/gender groups indicates that the approach of the current study - entering social class indicators into the model as covariates - is both theoretically and empirically justified: racial/ethnic/gendered opportunity structures shape access to resources that promote and exposure to risks that undermine health later-life health (O'Rand, 2006).

\section{Results \\ Bivariate race/ethnicity/gender differences}

As expected, race/ethnicity/gender groups were significantly different in the number of functional limitations at baseline (see Table 1). White Men had significantly fewer functional limitations (1.52) at baseline than any other race/ethnicity/gender group, on average. Black and Mexican American Women reported the greatest number of functional limitations at baseline, 3.16 and 3.35 limitations, respectively, and the two groups did not statistically differ from one another (not shown). Not surprisingly, across racial/ethnic groups Women had significantly more functional limitations at baseline than Men of the same race/ethnicity (Laditka and Laditka, 2002; Read and Gorman, 2006). At baseline, Black Men and Mexican American Men had similar levels of functional limitations that did not statistically differ (not shown).

As is evident from Table 1, racial/ethnic/gender groups also significantly differed in terms of life course capital. Compared to White Men, Blacks and Mexican Americans had disadvantaged childhoods. Mexican American Men and Women generally reported more disadvantaged socioeconomic circumstances in early life than did Black Men and Women (comparison not shown). This early life disadvantage was largely similar for Men and Women within each racial/ethnic group, although White Women had slightly less educated parents than did White Men. The pattern of inequality in adult SES largely mirrored that in early life, but in adulthood Women were generally more disadvantaged than Men of the same race/ethnicity. Health-related behaviors differed across racial/ethnic/gender groups in complex ways, consistent with prior studies (Rogers et al., 2000). For example, Black Women were significantly more likely to be obese, but were less likely to be heavy drinkers than any other racial/ethnic/gender group (not shown).

Overall, the pattern of group differences shows the privileged position of White Men in late mid-life and the general disadvantage faced by Women relative to Men. However, the descriptive results also show that there is considerable heterogeneity in life course capital between groups and that disadvantage is dependent on the indicator and the comparison group.

\section{Race/ethnicity/gender differences in trajectories of functional limitations}

We present estimates from random coefficient growth curve models of functional limitations in Table 2. Model 1 contains estimates for the effect of race/ethnicity/gender on the initial level and rate of change in functional limitations controlling only for nativity and panel attrition. Only the average fixed linear growth component is statistically significant when the slopes for the linear and quadratic terms are allowed to vary randomly across individuals (and, as described above, preliminary analyses indicated the need for random quadratic slopes). Substantively this indicates that while the average population rate of change is generally constant (i.e., a significant fixed linear term and non-significant fixed quadratic term), there are significant individual differences in the rate of the rate of change (i.e., a significant random effect for $\mathrm{Age}^{2}$ ) with some individuals experiencing an accelerating increase and others a decelerating increase in the rate of change. According to these estimates, at age 53, White Men had on average 0.85 functional limitations and their number of limitations increased 0.0615 on average for every one year increase in age on average, as indicated by the positive coefficient for the linear rate of change. By age 75 , White Men had more than tripled their level of functional impairment (2.62 limitations; calculations not shown). 
Table 2. Race/Ethnicity/Gender Trajectories of Functional Limitations Among Older Adults Ages 52 to 75: Random Coefficient Growth Curve Models $(N=8701)$.

\begin{tabular}{|c|c|c|c|c|c|}
\hline & Model 1 & Model 2 & Model 3 & Model 4 & Model 5 \\
\hline \multicolumn{6}{|l|}{ Fixed Effects ${ }^{\mathrm{a}}$} \\
\hline Intercept & $0.8529 * * *$ & $1.0265^{* * *}$ & $1.5633^{* * *}$ & $0.5169 * * *$ & $1.3921^{* * *}$ \\
\hline \multicolumn{6}{|l|}{ Race/Ethnicity/Gender Group ${ }^{b}$} \\
\hline White Women & $0.8482^{* * *}$ & $0.8450 * * *$ & $0.6433^{* * *}$ & $0.9314^{* * *}$ & $0.7269^{* * *}$ \\
\hline Black Men & $0.4051^{*}$ & 0.1982 & -0.0575 & $0.4014^{*}$ & -0.1073 \\
\hline Black Women & $1.4412^{* * *}$ & $1.2266^{* * *}$ & $0.9561^{* * *}$ & $1.4417^{* * *}$ & $0.8862 * * *$ \\
\hline Mexican American Men & $0.5934^{*}$ & 0.2983 & -0.3729 & $0.5644^{*}$ & -0.4235 \\
\hline Mexican American Women & $2.0079 * * *$ & $1.7267^{* * *}$ & $0.8169^{* * *}$ & $2.0663^{* * *}$ & $0.8372^{* * *}$ \\
\hline Linear Slope $(\text { Age })^{\mathrm{b}}$ & $0.0615^{\star * *}$ & $0.0593^{* * *}$ & $0.0384^{* * *}$ & $0.0584^{* * *}$ & 0.0340 ** \\
\hline White Women & -0.0072 & -0.0083 & -0.0074 & -0.0072 & -0.0078 \\
\hline Black Men & -0.0105 & -0.0120 & -0.0186 & -0.0100 & -0.0173 \\
\hline Black Women & $0.0617^{*}$ & $0.0610^{*}$ & $0.0516^{*}$ & $0.0626^{* *}$ & $0.0537^{*}$ \\
\hline Mexican American Men & 0.0599 & 0.0586 & 0.0574 & 0.0581 & 0.0568 \\
\hline Mexican American Women & 0.0000 & 0.0011 & -0.0010 & -0.0008 & 0.0001 \\
\hline Quadratic Slope $\left(\text { Age }^{2}\right)^{\mathrm{b}}$ & 0.0008 & 0.0009 & 0.0008 & 0.0009 & 0.0008 \\
\hline White Women & 0.0006 & 0.0007 & 0.0008 & 0.0006 & 0.0008 \\
\hline Black Men & 0.0009 & 0.0009 & 0.0010 & 0.0008 & 0.0010 \\
\hline Black Women & $-0.0028^{*}$ & $-0.0027^{*}$ & $-0.0023^{*}$ & $-0.0028^{*}$ & $-0.0024^{*}$ \\
\hline Mexican American Men & -0.0025 & -0.0024 & -0.0026 & -0.0025 & -0.0026 \\
\hline Mexican American Women & 0.0007 & 0.0007 & 0.0007 & 0.0008 & 0.0008 \\
\hline \multicolumn{6}{|l|}{ Early Life Social Origins } \\
\hline Family was Poor & & $0.3893^{* * *}$ & & & $0.2497^{* * *}$ \\
\hline Mother had $\geq$ H.S. Education & & $-0.2673^{* * *}$ & & & -0.0517 \\
\hline Father had $\geq$ H.S. Education & & $-0.3631^{* * *}$ & & & $-0.1697^{* *}$ \\
\hline \multicolumn{6}{|l|}{ Adult Socioeconomic Status } \\
\hline Years of Education & & & $-0.1652^{* * *}$ & & $-0.1459^{* * *}$ \\
\hline Earnings (Ln) & & & $-0.0274^{* * *}$ & & $-0.0277^{* * *}$ \\
\hline Social Security Income (Ln) & & & $0.0231^{*}$ & & $0.0219^{*}$ \\
\hline Net Worth (Ln) & & & $-0.2651^{* * *}$ & & $-0.2534^{* * *}$ \\
\hline In the Labor Force & & & $-0.5643^{* * *}$ & & $-0.5619^{* * *}$ \\
\hline Uninsured & & & $-0.0754^{*}$ & & $-0.0732^{*}$ \\
\hline \multicolumn{6}{|l|}{ Marital Status } \\
\hline Divorced & & & $0.2701^{* * *}$ & & $0.2481^{* * *}$ \\
\hline Widowed & & & 0.0766 & & 0.0533 \\
\hline Never Married & & & 0.1010 & & 0.0929 \\
\hline \multicolumn{6}{|l|}{ Health-Related Behaviors } \\
\hline Obese $(\mathrm{BMI} \geq 30)$ & & & & $0.3636^{* * *}$ & $0.3547^{* * *}$ \\
\hline Ever Smoked & & & & $0.4526^{* * *}$ & $0.3367^{* * *}$ \\
\hline Currently Smokes & & & & $-0.1463^{* * *}$ & $-0.1622^{* * *}$ \\
\hline Heavy Drinker (3 + Drinks/Day) & & & & -0.0669 & -0.0531 \\
\hline \multicolumn{6}{|l|}{ Controls } \\
\hline $\begin{array}{l}\text { Immigrant } \\
\text { Attrition }\end{array}$ & $-0.3383^{* * *}$ & $-0.3165^{\star *}$ & $-0.5249 * * *$ & $-0.2945^{* *}$ & $-0.4558^{* * *}$ \\
\hline Measurement Occasions & 0.0191 & 0.0180 & $0.0322^{*}$ & 0.0149 & 0.0197 \\
\hline Died during Observation & $1.8039 * * *$ & $1.7699 * * *$ & $1.4750 * * *$ & $1.7569 * * *$ & $1.4576^{* * *}$ \\
\hline \multicolumn{6}{|l|}{ Random Effects } \\
\hline Level 2 Intercept (s0i) & $4.2482^{* * *}$ & $4.1372^{* * *}$ & $3.5207^{* * *}$ & $4.1718^{* * *}$ & $3.4338^{* * *}$ \\
\hline Level 2 Age $(s 1 \mathrm{i})$ & $0.0565^{* * *}$ & $0.0567^{* * *}$ & $0.0542 * * *$ & $0.0568^{* * *}$ & $0.0545^{* * *}$ \\
\hline Level 2 Age $^{2}\left(\mathrm{~s}^{2} \mathrm{i}\right)$ & $0.0001^{* * *}$ & $0.0001^{* * *}$ & $0.0001^{* * *}$ & $0.0001^{* * *}$ & $0.0001^{* * *}$ \\
\hline Level 1 Residual (cij) & $1.6592^{* * *}$ & $1.6595^{* * *}$ & $1.6626^{* * *}$ & $1.6600^{* * *}$ & $1.6630^{* * *}$ \\
\hline 2 Log Likelihood & 187019.6 & 186801.1 & 185553.7 & 186754.0 & 185262.8 \\
\hline
\end{tabular}

${ }^{*} p<0.05,{ }^{* *} p<0.01,{ }^{* * *} p<0.001$. Source: 1994-2006 US Health and Retirement Study.

a. Models 2 and 5 also control for missing on Family was Poor, Mother's Education, and Father's Education

b. White Men serves as the reference group.

Consistent with the bivariate pattern discussed above, the initial level of functional limitations varied significantly by race/ethnicity/gender and all groups had significantly more functional limitations than White Men. The magnitude of difference was generally smaller among Men, with Black Men having 0. 41 more limitations and Mexican American Men 0.59 more limitations at age 53 than White Men on average (the difference between Black and Mexican American Men was not statistically significant; not shown). By contrast, and consistent with the well-known gender disparity in disability (Laditka \& Laditka, 2002), Women had much higher levels of functional limitations at age 53 than did White Men. White Women had 0.85 more limitations on average than White Men, compared to 1.44 and 2.01 more limitations for Black and Mexican American Women, respectively. Mexican American Women had the greatest number of functional impairments at baseline with 2.86 limitations - more three times the level exhibited by
White Men. Indeed, the parameter estimates in Model 1 indicate that Mexican American Women had more functional limitations at age 53 than White Men had at age 75 (calculation not shown).

These large differences in the initial level of functional limitations aside, the age-associated rate of change in functional limitations generally did not significantly vary by race/ethnicity/gender - with the exception of the rate for Black Women. Thus, net of the controls for nativity and panel attrition, White Men, White Women, Black Men, Mexican American Men, and Mexican American Women have statistically similar rates of change in functional limitations with age. For Black Women, however, both parameters for the linear and quadratic slopes are statistically significant and indicate that the average growth in functional impairment with age for older Black Women follows pattern distinct from that experienced by other race/ethnicity/gender groups. Combined, these pa- 


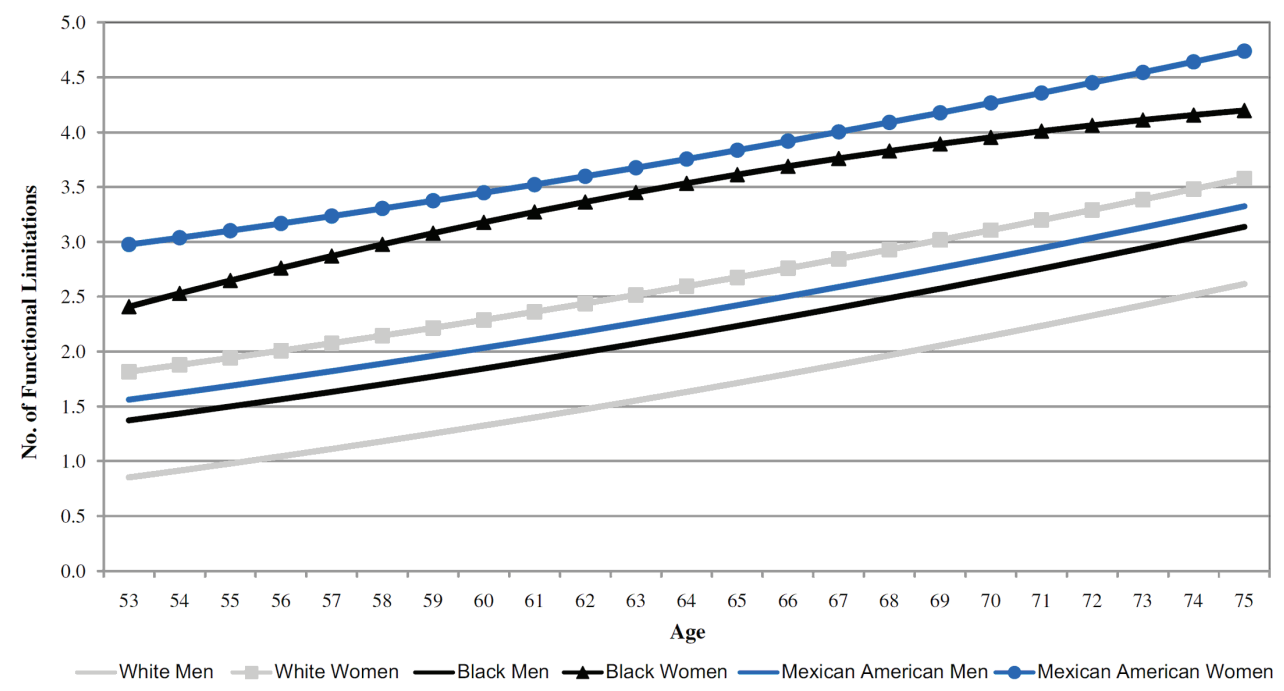

Figure 1. Age-Trajectories of Functional Limitations by Race/Ethnicity/Gender, Growth Curve Model Estimates Using the 1994-2006 US Health and Retirement Study. Age-trajectories implied for respondents observed at all interview waves and plotted using the fixed effects for the intercept, linear and quadratic slopes, and the statistically significant coefficients for their interaction with each race/ethnicity/gender group in Model 1 of Table 2; Mexican American Men do not significantly differ from White Women or Black Men, all other groups comparisons are significantly different.

rameter estimates indicate that the mean rate of change for Black Women is increasing (positive linear growth parameter) at a decreasing rate (negative quadratic growth parameter) compared to that of other groups. That is, while the fixed linear slope coefficient indicates that Black Women on average experience an additional increase of 0.0617 limitations for every one year increase in age (about double the rate experienced by other groups), the quadratic coefficient indicates that this mean linear rate decreases on average by 0.0028 for each one year increase in age. This non-linear rate of change in functional limitations for Black Women is graphically presented in Figure 1, alongside the implied rates of change for Whites, Black Men, and Mexican Americans.

Thus, as depicted in Figure 1, the growth curve estimates in Model 1 generally indicate that the disparity in functional limitations is relatively similar with age for White Men and Women, Black Men, and Mexican American Men and Women, with each group increasing at roughly the same rate. Black Women, by contrast, accumulate functional limitations more rapidly than these groups through the mid 60s, after which they gain proportionately fewer impairments with each additional year of age.

In supplementary analyses (not shown), we rotated the reference groups to check the robustness of our findings and these models were generally consistent with our interpretation: White Men and Women, Black Men, and Mexican American Men and Women have statistically indistinguishable rates of change in functional limitations regardless of reference group. The unique age trajectory experienced by Black Women is also robust to the choice of reference groups, but we note that the fixed effects for the linear and quadratic rates of change did not statistically differ from those of Mexican American Men and Women - though we caution against making any contrary conclusions given relatively small samples of these two groups.

The unique disability experience of Black Women with age highlights the importance of an intersectionality approach for studying health trajectories. Nevertheless, because the absolute differences in functional impairments between Black Women and other race/ethnicity/gender groups are of similar magnitude at ages 53 and 75 (not shown), and these other racial/ethnic/gender groups have constant differences with age, the pattern implied by the growth curve estimates is best described as persistent inequality. While extrapolations from the age-trajectories of impairment for Black Women displayed in Figure 1 would imply that Black Women will have fewer limitations than White Women or Men of any race/ethnicity at some advanced age, such an interpretation is well-outside the observed age-range on which the modeled age-related changes are based and thus cannot be made from the findings presented.

We added indicators of early life social origins, adult SES, marriage, and health behaviors to determine the extent to which these forms of life course capital could explain the persistent inequality in trajectories of functional limitations across race/ethnicity/gender groups. As the estimates from the models where the blocks of life course capital indicators were entered separately (Models 2-4) are largely similar, we focus on the results from to the combined model (Model 5).

Overall, differences in life course capital fully explain racial/ethnic disparities in the initial level of functional limitations among Men but only partially explain those among Women $-\mathrm{a}$ finding that has appeared in a few prior studies (Mendes de Leon et al., 2005; Read and Gorman, 2006). Net of early life social origins, adult SES, marriage and health-related behaviors, the initial level of functional impairments for Black and Mexican American Men are no longer statistically different from that of White Men, which-when combined with the fact that their rates of change with age also do not differmeans that Men of all racial ethnic groups experience similar trajectories of functional limitations from about ages 53 to 75 . While the introduction of early life social origins reduced the coefficients for Black and Mexican American Men to statistical non-significance (Model 2), adult SES and marital status (Model 3) fully accounted for the disparities in the initial level of functional limitations among Men, substantially reducing the intercept variance, and resulted in estimates that are close in magnitude to those in the combined model. Moreover, the estimates in Model 5 for the early life indicators are 36\%-80\% smaller than those in Model 2 indicating that early life affects functional limitations, at least partially, through adult achievement (Warner \& Hayward, 2006).

Comparing the coefficients between Models 1 and 5 reveals that the unequal distribution of early life social origins, adult SES, marriage and health-related behaviors eliminated approximately $39 \%$ of the elevated level of functional limitations experienced by Black Women and 58\% of that experienced by Mex- 
ican American Women relative to White Men at age 53. The addition of these controls explained just $12 \%$ of the greater functional impairment of White Women. Net these various forms of life course capital, Black and Mexican American Women were no longer significantly different from one another in terms of their the initial level of functional limitations (not shown). As with Men, the reductions in the initial level of functional impairment were largely due to the unequal distribution of adult socioeconomic resources and differences in marital status between, White, Black, and Mexican American Women.

Accounting for adult SES and marriage alone explained a slightly greater percentage of the disparities in functional limitations among White and Mexican American Women than the complete model with health-related behaviors included (compare Models 4 and 5). This is not surprising given the generally worse behavioral profiles of Men relative to Women (esp. smoking), but does suggest that the better health-related behaviors of Women, overall, keeps the gap in functional limitations from being greater. Controlling for health behaviors had no effect of Black Women's initial level of functional limitations.

Comparing the age parameters between Models 1 and 5 shows that accounting for disparities in life course capital reduced the average linear increase in functional limitations with age by about $44 \%$ - that is, a slower accumulation of functional limitations with age. Yet, Black Women's age trajectory of functional impairment remained distinct even after controlling for differences in life course capital, as both the linear and quadratic growth parameters for Black Women were still statistically significant. Indeed, controlling for life course capital reduced the average additional linear slope experienced by Black Women by just $13 \%$. Thus, compared to other racial/ethnic/ gender groups, controlling for life course capital revealed an even steeper instantaneous linear slope for Black Women - who at the beginning of their early 50 s acquire functional limitations at 2.58 times the rate of other racial/ethnic/gender groups. Again, the average rate of change in functional limitations for Black Women decreased by 0.0024 with each additional year in age. Thus, despite the fact that adjusting for life course capital eliminated the racial/ethnic disparities among Women in the initial levels of functional impairment at age 53 (not shown), Black Women experience disablement much more quickly than White or Mexican American Women. However, net of differences in life course capital, the trajectories of impairment experienced by White and Mexican American Women "catch up" to that of Black Women as there were no racial/ethnic differences in the level of impairment at age 75 either (not shown).

Examining the effects of the covariates for life course capital on the initial level of impairment in the final model (Model 5), we found that the effects of early life circumstances, adult SES, marriage and health-related behaviors on trajectories of functional impairment were largely consistent with prior studies. Persons who felt their families were poor relative to others when growing up and those with less educated fathers had more limitations. Adult socioeconomic resources-education, earnings, and net worth - were all associated with fewer functional limitations. Persons in the labor force also had fewer functional limitations, while those receiving Social Security income had more functional limitations. Interestingly, those who lacked health insurance had fewer limitations. Obese respondents and former and current smokers also had higher levels of functional impairment. Immigrants had fewer limitations. Not surprisingly, respondents who died during the observation had significantly more functional limitations.

\section{Discussion}

This study advanced the understanding of racial/ethnic/ gender disparities in health changes among older adults, us- ing data from the 1994-2006 US Health and Retirement Study and bridging intersectionality and life course theories. An intersectionality approach stipulates that race/ethnicity and gender jointly and simultaneously define access to life chances and reinforce one another in multiple ways in the production and maintenance of health across the life course (Mullings \& Schulz, 2006). Accordingly, we systematically investigated the effect of race/ethnicity/gender on age-trajectories of functional limitations among White, Black, and Mexican American Men and Women and examined the extent to which disability disparities stem from socially constructed differential access to life course capital. Similar to prior studies, we found substantial racial/ ethnic/gender disparities in the number of functional limitations. White Men had the lowest number of functional limitations, while Mexican American Women had the greatest number of functional limitations. The magnitude of difference was narrower among Men than among Women overall, as Black and Mexican American Women had substantially more functional limitations than Men of any race or White Women. Moreover, we found that for White Men and Women, Black Men, and Mexican American Men and Women these initial disparities were on average constant with age, as each group experienced a similar rate of increase in functional limitations.

Black Women, by contrast, experienced a different disability age-trajectory, one that may be characterized as accelerated disablement. With high levels of initial impairment, Black Women experience a more rapid accumulation of functional limitations though the mid 60s than other groups. However, rather than this trajectory of impairment continuing to diverge, between the mid 60s and mid 70s the gap between Black Women and other groups actually declined because the rate of acceleration for Black Women slowed such that disability trajectories experienced by other groups had "caught up" to the early progression experience by Black Women. Thus, our growth curve estimates indicate that the absolute differences in functional impairments between Black Women and other race/ethnicity/gender groups were of similar magnitude at ages 53 and 75 .

The social mechanism behind the more rapid accumulation of functional impairment with age for Black Women in their 50 s and early 60 s is unclear. Prior studies suggest a number of factors - perceived discrimination, earlier and greater caregiving responsibilities among some families, elevated levels of stress hormones, segregation in disadvantaged neighborhoods (Burton, 1996; Collins and Williams, 1999; Geronimus, 2001; Geronimus et al., 2006) - may be at the source of the differential trajectories of disability for Black Women; although, it is important to point out that these explanations have typically been offered for patterns of divergence not evident in our data. Examination of whether these possibilities can explain the earlier and accelerated disablement of Black Women was beyond the scope of the present study and unfortunately the HRS did not collect information on perceived racism or self-reported neighborhood characteristics until the most recent interview, precluding growth curve analysis. Further research is needed to test whether these risk factors generate Black Women's average trajectory of accelerated disablement.

Our growth curve estimates are most consistent with an interpretation of persistent inequality, rather than cumulative disadvantage or aging-as-leveler. The caveat to the interpretation of persistent inequality, of course, is that while the absolute differences in impairment are similar between racial/ ethnic/gender groups at ages 53 and 75, we find that Black Women experience a pattern of accelerated disablementwith a more rapid progression of impairment relative to other groups during the intervening years. Our finding of persistent inequality is largely in agreement with Taylor (2008), who found in a sample of North Carolina elders over the age of 65 
that Blacks do not experience a divergent trajectory of functional impairment over time (see also Ferraro and Farmer, 1996b; Kelley-Moore and Ferraro, 2004). We note that Taylor (2008) used a two-part growth curve model to estimate the onset and growth of ADL and IADL disability as separate processes and found that race disparities in disability were solely a function of earlier onset among Blacks. In supplemental analyses, we tested this possibility by estimating the impact of race/ethnicity on the accumulation of functional impairments among the subsample of respondents that already had at least one limitation and thereby focusing only on the "growth" component of Taylor's (2008) model. These analyses revealed that racial/ethnic/gender patterns - including the accelerated disablement experienced by Black Women-observed in the entire sample were present in this select sub-sample and the indicators of life course capital behaved similarly.

The finding of persistent inequality in disability trajectories among racial/ethnic/gender groups is in contrast to a few prior studies documenting divergence in age-trajectories (Kim and Durden, 2007; Mendes de Leon et al., 2005), and may be because we estimated trajectories in a sample of the youngold rather than a sample of persons over the age of 75 . As the birth cohort examined here ages, it will be important for future studies to determine if this pattern of divergence (or even one of aging-as-leveler) emerges. Nonetheless, because the absolute differences in functional impairments between race/ ethnicity/gender groups were of similar magnitude at ages 53 and 75, our findings suggest that disparities in disability generally emerge in midlife and are carried forward into old age (Brown \& Warner, 2008).

According to our findings, dissimilar early life social origins, adult SES, marital status, and health behaviors combine to explain substantially the racial/ethnic/gender disparities in functional limitations. However, as suggested by previous studies (Fuller-Thomson et al., 2009; Mendes de Leon et al., 2005; Read and Gorman, 2006), these factors explain the racial/ethnic disparities in functional limitations among Men but only partially explain the disparities among Women. Net of indicators of life course capital, Women of all racial/ethnic groups have higher levels of initial functional limitations relative to White Men and Men of the same race/ethnicity. The persistence of the gender gap in functional limitations is consistent with prior studies (Newman \& Brach, 2001) and may reflect, for example, a biological component to impairment or gender differences in assessment of limitations (Verbrugge, 1989). Although beyond the scope of the current study, evidence from prior studies - including inconsistency in sex-differences in underlying chronic conditions and physical symptoms and variability in the magnitude of disparities across health outcomes and across countries (Arber and Cooper, 1999; Macintyre et al., 1996) - suggests considerable complexity in gender differences in health and cut against purely biological explanations. Moreover, as detailed by Verbrugge and Jette (1994), disablement is inherently a social process, stemming from a mismatch between personal physical abilities and the demands of one's environment. The findings here continue to signal the need for additional research into of the social context of gender differences in disability (Verbrugge, 1989; Verbrugge and Jette, 1994).

Our results-especially the unique age-trajectory of accelerated impairment experienced by Black Women relative to other groups - demonstrate unequivocally that racial/ethnic disparities in disability trajectories are conditioned by gender, the origins of racial/ethnic disparities are gendered, and accordingly an intersectionality approach to the study of health disparities is needed to better understand the social construction of health in later life. In addition to this intersectionality approach, the current study made several methodological improvements over prior examinations and advanced our un- derstanding of inequality in health change. First, we modeled intra-individual change between ages 53 and 75 in terms of age-trajectories using data from a narrow set of birth cohorts (1931-1941), which were followed over 12 years and consequently yielded considerable age-overlap across cohorts. By contrast, many prior longitudinal analyses of racial/ethnic and gender disparities have employed accelerated cohort designs to model intra-individual change. Accelerated cohort designs involve an age-heterogeneous initial sample (i.e., many different birth cohorts) followed longitudinally and the respondents are treated as a synthetic cohort. Such designs are common in the study of health disparities (see Herd, 2006; Shuey and Willson, 2008; Willson et al., 2007). However, given cohort differences in the exposure to health risks and socioeconomic resources (Costa, 2002), such a modeling approach is problematic when there are few observations and the follow-up period is not lengthy enough to provide substantial age-overlap across cohorts (e.g., Kim and Miech, 2009; Liang et al., 2008). Moreover, mortality selection processes (Dupre, 2007) mean that the oldest panel members, from the earliest birth cohorts, represent a select group of survivors least likely to have functional limitations. Indeed, a second strength of the current study is that within the context of our prospective cohort study we explicitly accounted for mortal and non-mortal panel attrition in the estimation of these age-trajectories.

The present study also advanced our understanding of inequality in health trajectories by examining the experiences of Mexican American Men and Women. Prior research on disability trajectories has largely focused on differences only between Blacks and Whites (e.g., Ferraro and Farmer, 1996b; Kelley-Moore and Ferraro, 2004; Kim and Miech, 2009; Taylor, 2008) or when not limited to these two groups has examined an amorphous Hispanic category (e.g., Liang et al., 2008). Failure to examine specific Hispanic-origin groups (i.e., Mexican Americans, Puerto Ricans, Cuban Americans, etc.) clouds our understanding of health disparities because both health status and socioeconomic resources vary widely across these groups (see Markides et al., 2007; Read and Gorman, 2006). Documenting health trajectories of older Mexican Americans is especially important given their projected increase as a share of the U.S. population over the next several decades (Angel \& Whitfield, 2007). Nevertheless, despite oversampling in the HRS, the samples of Mexican American Men and Women were quite small and our findings with respect to this group should be regarded as preliminary and interpreted with caution.

Despite these advances, this study leaves several important questions unaddressed. First, our examination of racial/ ethnic/gender disparities in health trajectories was confined to functional limitations. As the nature and magnitude of health disparities depends on the health measure employed (Macintyre et al., 1996; Read and Gorman, 2006), additional studies using an intersectionality approach are needed to examine other health indicators - such as chronic conditions, self-ratedhealth, and depressive symptoms - to determine whether the racial/ethnic/gender patterns we document here are applicable to a wide array of health phenomena.

Second, we limited our analysis to just one group of Hispanics-Mexican Americans. However, it will be important for future research, with data explicitly suited to such purposes, to examine age-trajectories of health among Mexican American and other Hispanic groups. Prior studies consistently indicate that Puerto Ricans have worse health profiles than Mexican Americans, while Cuban American have better profiles (Read \& Gorman, 2006). The extent to which these subgroup differences manifest themselves similarly in a prospective study of health change is unclear.

Third, in the present study we controlled for immigrant status in our multivariate models. Yet, because the immi- 
grant health advantage is apparent, albeit to differing degrees, across racial/ethnic/gender groups (Hummer et al., 1999; Palloni and Arias, 2004), future studies are needed to examine explicitly the role of nativity in shaping health trajectories among older adults. Such studies should employ an intersectionality approach - specifying racial/ethnic/gender/nativity groups - to understand how the complex allocation of material and relational forms of life course capital among various immigrant groups affects their health trajectories.

Fourth, although we control for prospective mortal and nonmortal panel attrition, left-censoring may be an issue. Our results presented may be biased given racial/ethnic/gender differences in mortality rates and the fact that health disparities begin to manifest in mid-life (Brown and Warner, 2008; House et al., 1994) prior to inclusion in the HRS sample. Accordingly, our findings are conditional upon survival to midlife and should be interpreted as such. However, mortality selection processes are apt to be less severe here than in accelerated cohort designs where survival to age 70 or greater is required for the initial inclusion. Nevertheless, future research should investigate racial/ethnic/gender differences in health trajectories and the factors that generate them earlier in the life course in order to better understand and eliminate health disparities.

Finally, our examination of racial/ethnic/gender age-trajectories of disability focused exclusively on between-group differences. We, as have most prior studies using similar methods (e.g., Haas, 2008; Kahng et al., 2004; Kim and Durden, 2007; Liang et al., 2008), have left unexamined how heterogeneous age-trajectories of disability are within-groups (KelleyMoore \& Lin, 2011). Indeed, the social construction of race/ ethnicity and gender (See note 1) results in the presumption of homogeneity within these socially meaningful racial/ethnic/ gender groups (Calasanti, 1996; Williams et al., 1994). Yet it is unrealistic to assume that every individual within a racial/ ethnic/gender group experiences the same patterns of intraindividual change over time or that the patterns of variability in these trajectories would be the same across groups, given the social patterning of life course capital and risks. While the extent of such within-group heterogeneity does not challenge our findings of average between-group differences in the agetrajectories of the groups we study, future research would be well-served to examine how much variability exists within racial/ethnic gender groups to gain greater understanding of the social process that lead to inequality in health differentiation with age.

Overall, the present study adds to a small but growing number of quantitative examinations of longitudinal health disparities using an intersectionality approach. While prior studies have demonstrated wide disparities in health and functional limitations among racial/ethnic groups (Ferraro and Farmer, 1996b; Kelley-Moore and Ferraro, 2004; Kim and Miech, 2009) or by gender (Anderson et al., 1998; Guralnik and Kaplan, 1989; Kahng et al., 2004), our findings highlight the utility of investigating how race/ethnicity and gender intersect or combine to affect the health of older adults. Race/ethnicity and gender are not separate dimensions of social stratification (Thornton Dill \& Zambrana, 2009) but rather jointly and simultaneously define both access to the resources that promote health and exposure to the risks that undermine health across the life course (Mullings and Schulz, 2006; Read and Gorman, 2006). The application of an intersectionality approach provides a more detailed understanding of the social stratification of health and age-related changes in health, yielding relationships that are otherwise obscured when race/ethnicity and gender are examined in a separate fashion, and will better inform prevention efforts aimed at eliminating what have thus far proven to be entrenched health disparities.
Acknowledgments - Research support was provided to the first author in part by NIH grant T32 AG00155 through the Carolina Population Center at the University of North Carolina at Chapel Hill. Additional support was provided to the second author by NIH Grant T32 AG00029 at the Duke Center for the Study of Aging and Human Development and the Robert Wood Johnson Foundation Center for Health Policy at Meharry Medical College (RWJF Grant 64300 and sub-award 100927DLH216-02). An earlier version of this paper was presented at the 75th Annual Meeting of the Population Association of America, Dallas, TX, April 15-17, 2010. We thank Bridget K. Gorman, Jessica Kelley-Moore, Miles G. Taylor, and Tara D. Warner for helpful comments and suggestions on prior drafts.

\section{References}

Alwin, D. F., Hofer, S. M., \& McCammon, R. J. (2006). Modeling the effects of time: integrating demographic and developmental perspectives. In R. H. Binstock, \& L. K. George (Eds.), Handbook of aging and the social sciences (6th ed.). (pp. 20-38) San Diego: Academic Press.

Anderson, R. T., James, M. K., Miller, M. E., Worley, A. S., \& Longino, C. F., Jr. (1998). The timing of change: patterns in transitions in functional status among elderly persons. Journal of Gerontology: Social Sciences, 53B(1), S17-S27.

Angel, J. L., \& Whitfield, K. E. (2007). The health of aging Hispanics: The Mexican-origin population. New York: Springer.

Arber, S., \& Cooper, H. (1999). Gender differences in health in later life: the new paradox? Social Science \& Medicine, 48(1), 61-76.

Azpitarte, F. (2010). Measuring poverty using both income and wealth: A cross-country comparison between the U.S. and Spain (ECINEQ Working Paper, No. 2010-153). Palma de Mallorca, Spain: Society for the Study of Economic Inequality.

Bird, C. E., \& Rieker, P. P. (1999). Gender matters: an integrated model for understanding men's and women's health. Social Science \& Medicine, 48, 745-755.

Blackwell, D. L., Collins, J. G., \& Coles, R. (2002). Summary health statistics for U.S. Adults: national health interview survey, 1997. InVital and health statistics, Vol. 10:205. National Center for Health Statistics.

Brady, D. (2009). Rich democracies, poor people: How politics explain poverty. New York: Oxford University Press.

Brown, T., \& Warner, D. F. (2007, March 28-31). Divergent pathways? A life course study of racial/ethnic differences in women's labor force withdrawal. Paper presented at the. New York, NY: Population Association of America.

Brown, T. H., \& Warner, D. F. (2008). Divergent pathways? A life course study of racial/ethnic differences in women's labor force withdrawal. Journal of Gerontology: Social Sciences, 63B(3), S122-S134.

Burton, L. M. (1996). Age norms, the timing of family role transitions, and intergenerational caregiving among aging African American women. The Gerontologist, 36(2), 199-208.

Calasanti, T. M. (1996). Incorporating diversity: meaning, levels of research, and implications for theory. The Gerontologist, 36, 147-156.

Clark, D. O., \& Maddox, G. L. (1992). Racial and social correlates of age-related changes in functioning. Journal of Gerontology, 47(5), S222.

Collins, C. A., \& Williams, D. R. (1999). Segregation and mortality: the deadly effects of racism? Sociological Forum, 14(3), 495-523.

Costa, D. L. (2002). Changing chronic disease rates and long-term declines in functional limitation among older men. Demography, 39(1), 119-137. 
Dannefer, D. (1987). Aging as intracohort differentiation: accentuation, the Matthew effect, and the life course. Sociological Forum, 2, 211-236.

Dupre, M. E. (2007). Educational differences in age-related patterns of disease: reconsidering the cumulative disadvantage and age-as-leveler hypotheses. Journal of Health and Social Behavior, 48(1), 1-15.

Elder, G. H., Jr., Johnson, M. K., \& Crosnoe, R. (2003). The emergence and development of life course theory. In J. T. Mortimer, \& M. J. Shanahan (Eds.), Handbook of the life course (pp. 3-19). New York: Kluwer Academic/Plenum Publishers.

Farmer, M. M., \& Ferraro, K. F. (2005). Are racial disparities in health conditional on socioeconomic status? Social Science $\mathcal{E}$ Medicine, 60(1), 191-204.

Ferraro, K. F., \& Farmer, M. M. (1996a). Double jeopardy to health hypothesis for African Americans: analysis and critique. Journal of Health and Social Behavior, 37, 27-43.

Ferraro, K. F., \& Farmer, M. M. (1996b). Double jeopardy, aging as level, or persistent health inequality? A longitudinal analysis of white and black Americans. Journal of Gerontology: Social Sciences, 51B, S319-S328.

Ferraro, K. F., \& Kelley-Moore, J. A. (2003). Cumulative disadvantage and health: long-term consequences of obesity? American Sociological Review, 68(5), 707-729.

Ferraro, K. F., Thorpe, R. J., Jr., McCabe, G. P., Kelley-Moore, J. A., \& Jiang, Z. (2006). The color of hospitalization over the adult life course: cumulative disadvantage in black and white? Journal of Gerontology: Social Sciences, 61B(6), S299-S306.

Fuller-Thomson, E., Nuru-Jeter, Minkler, M., \& Guralnik, J. M. (2009). Black-white disparities in disability among older Americans: Further untangling the role of race and socioeconomic status. Journal of Aging and Health, 21(5), 677-698.

George, L. K. (2009). Conceptualizing and measuring trajectories. In G. H. J. Elder, \& J. Z. Giele (Eds.), The craft of life course research (pp. 163-186). New York: The Guilford Press.

Geronimus, A. T. (2001). Understanding and eliminating racial inequalities in women's health in the United States: the role of the weathering conceptual framework. Journal of the American Medical Women's Association, 56, 133-136.

Geronimus, A. T., Hicken, M., Keene, D., \& Bound, J. (2006). 'Weathering' and agepatterns of allostatic load scores among blacks and whites in the United States. American Journal of Public Health, 96, 826-833.

Gorman, B., \& Read, J. n. G. (2006). Gender disparities in adult health: an examination of three measures of morbidity. Journal of Health and Social Behavior, 47 (June), 95-110.

Greenlund, K. J., Giles, W. H., Keenan, N. L., Croft, J. B., Casper, M. L., \& Matson- Koffman, D. (1998). Prevalence of multiple cardiovascular disease risk factors among women in the United States, 1992 and 1995: the behavioral risk factor surveillance system. Journal of Women's Health, 7(9), 1125-1133.

Guralnik, J. M., \& Kaplan, G. A. (1989). Predictors of healthy aging: prospective evidence from the alameda county study. American Journal of Public Health, 79, 703-708.

Haas, S. A. (2008). Trajectories of functional health: the 'long arm' of childhood health and socioeconomic factors. Social Science $\mathcal{E}$ Medicine, 66(4), 849-861.

Hayward, M. D., Crimmins, E. M., Miles, T. P., \& Yu, Y. (2000). The significance of socioeconomic status in explaining the racial gap in chronic health conditions. American Sociological Review, 65, 910-930.

Hayward, M. D., Friedman, S., \& Chen, H. (1996). Race inequities in men's retirement. Journal of Gerontology: Social Sciences, 51, S1-S10.

Hayward, M. D., \& Heron, M. (1999). Racial inequality in active life among adult Americans. Demography, 36, 77-91.
Hayward, M. D., \& Warner, D. F. (2005). The demography of population health. In D. Poston, \& M. Micklin (Eds.), The handbook of population. New York: Springer.

Hayward, M. D., Warner, D. F., \& Crimmins, E. M. (2007). Does longer life mean better health? Not for native-born Mexican Americans in the Health and Retirement Study. In J. L. Angel, \& K. E. Whitfield (Eds.), The health of aging Hispanics: The Mexicanorigin population (pp. 85-95). New York: Springer.

Heckman, J. J. (1979). Sample selection bias as a specification error. Econometrica, 47, 153-162.

Herd, P. (2006). Do health inequalities diminish in old age? Educational status and functional decline among the 1931-1941 birth cohort. Research on Aging, 28, 375-392.

Hirschman, C., Alba, R., \& Farley, R. (2000). The meaning and measurement of race in the U.S. Census: glimpses into the future. Demography, 37(3), 381-393.

House, J. S., Lepkowski, J. M., Kinney, A. M., Mero, R. P., Kessler, R. C., \& Herzog, A. R. (1994). The social stratification of aging and health. Journal of Health and Social Behavior, 35, $213-234$

HRS. (2006). Survey design and performance. Accessed November 9, 2006, from. http://hrsonline.isr.umich.edu/intro/sho intro. php?hfyle=uinfo

Hummer, R. A., Rogers, R. G., Amir, S. H., Forbes, D., \& Frisbie, W. P. (2000). Adult mortality differentials among Hispanic subgroups and non-Hispanic whites. Social Science Quarterly, 81, 459-476.

Hummer, R. A., Rogers, R. G., Nam, C. B., \& LeClere, F. B. (1999). Race/ethnicity, nativity, and U.S. Adult mortality. Social Science Quarterly, 80, 136-153.

Kahng, S. K., Dunkle, R. E., \& Jackson, J. S. (2004). The relationship between the trajectory of body mass index and health trajectory among older adults: multilevel modeling analyses. Research on Aging, 26(1), 31-61.

Kelley-Moore, J. A., \& Ferraro, K. F. (2004). The black/white disability gap: persistent inequality in later life? Journal of Gerontology: Social Sciences, 59(1), S34-S43.

Kelley-Moore, J. A., \& Ferraro, K. F. (2005). A 3-d model of health decline: disease, disability, and depression among black and white older adults. Journal of Health and Social Behavior, 46(December), 376-391.

Kelley-Moore, J. A., \& Lin, J. (2011). Widening the view: capturing "unobserved" heterogeneity in studies of age and the life course. In R. A. Settersten, Jr., \& J. L. Angel (Eds.), Handbook of sociology of aging (pp. 51-68). New York: Springer Science.

Kim, J., \& Durden, E. (2007). Socioeconomic status and age trajectories of health. Social Science \& Medicine, 65, 2489-2502.

Kim, J., \& Miech, R. (2009). The black-white difference in age trajectories of functional health over the life course. Social Science $\mathcal{E}$ Medicine, 68, 717-725.

Kuh, D., \& Ben-Shlomo, B. (1997). A life course approach to chronic disease epidemiology. New York: Oxford University Press.

Laditka, S. B., \& Laditka, J. N. (2002). Recent perspectives on active life expectancy for older women. Journal of Women $\mathcal{E}$ Aging, 14(1/2), 163-184.

Liang, J., Bennett, J. M., Shaw, B. A., Quiñones, A. R., Ye, W., Xu, $X$. , et al. (2008). Gender differences in functional status in middle and older age: are there any age variations. Journal of Gerontology: Social Sciences, 63B(5), S282-S292.

Little, R. J. A., \& Rubin, D. B. (1987). Statistical analysis with missing data. New York: John Wiley \& Sons.

Lorber, J. (1995). Paradoxes of gender. New Haven, CT: Yale University Press.

Macintyre, S., Hunt, K., \& Sweeting, H. (1996). Gender differences in health: are things really as simple as they seem? Social Science $\mathcal{E}$ Medicine, 42(4), 617-624. 
Maddox, G. L., \& Clark, D. O. (1992). Trajectories of functional impairment in later life. Journal of Health and Social Behavior, 33(2), 114-125.

Markides, K. S., Coreil, J., \& Rogers, L. (1989). Aging and health among southwestern Hispanics. In K. S. Markides (Ed.), Aging and health: Perspectives on gender, race, ethnicity and class (pp. 177210). Newbury Park, CA: Sage Publications.

Markides, K. S., Eschbach, K., Ray, L. A., \& Peek, M. K. (2007). Census disability rates among older people by race/ethnicity and type of Hispanic origin. In J. L. Angel, \& K. E. Whitfield (Eds.), The health of aging Hispanics: The Mexican-origin population (pp. 26-39). New York: Springer.

Markides, K. S., Rudkin, L., Angel, R. J., \& Espino, D. V. (1997). Health status of Hispanic elderly. In L. G. Martin, \& B. J. Soldo (Eds.), Racial and ethnic differences in the health of older Americans (pp. 285-300). Washington, D.C.: National Academy Press.

Martin, L. G., Schoeni, R. F., Freedman, V. A.,\&Andreski, P. (2007). Feelingbetter? Trends in general health status. Journal of Gerontology: Social Sciences, 62, S11-S21.

McGee, D., Cooper, R., Liao, Y., \& Durazo-Arvizu, R. (1996). Patterns of comorbidity and mortality risk in blacks and whites. Annals of Epidemiology, 6, 381-385.

Mendes de Leon, C., Barnes, L. L., Bienias, J. L., Skarupski, K. A., \& Evans, D. A. (2005). Racial disparities in disability: recent evidence from self-reported and performance- based disability measures in a population-based study of older adults. Journal of Gerontology: Social Sciences, 60B(5), S263-S271.

Moen, P., \& Spencer, D. (2006). Converging divergences in age, gender, health and well-being: strategic selection and the third age. In R. H. Binstock, \& L. K. George (Eds.), Handbook of aging and the social sciences (6th ed.). (pp. 127-144) Burlington, MA: Academic Press.

Mulatu, M. S., \& Schooler, C. (2002). Causal connections between socio-economic status and health: reciprocal effects and mediating mechanisms. Journal of Health and Social Behavior, 43(March), 22-41.

Mullings, L., \& Schulz, A. J. (2006). Intersectionality and health: an introduction. In L. Mullings, \& A. J. Schulz (Eds.), Gender, race, class, and health: An intersectional approach (pp. 3-17). San Francisco: John Wiley \& Sons, Inc.

Newman, A. B., \& Brach, J. S. (2001). Gender gap in longevity and disability in older persons. Epidemiologic Reviews, 23(2), 343-350.

O'Rand, A. M. (2006). Stratification and the life course: life course capital, life course risks, and social inequality. In R. H. Binstock, \& L. K. George (Eds.), Handbook of aging and the social sciences (6th ed.). (pp. 146-162) Burlington, MA: Academic Press.

Omi, M., \& Winant, H. (1994). Racial formations in the United States (2nd ed.). New York: Routledge.

Palloni, A., \& Arias, E. (2004). Paradox lost: explaining the Hispanic adult mortality advantage. Demography, 41(3), 385-415.
Raudenbush, S. W., \& Bryk, A. S. (2002). Hierarchical linear models: Applications and data analysis methods (2nd ed.). Thousand Oaks, CA: Sage Publications, Inc.

Read, J. n. G., \& Gorman, B. (2006). Gender inequalities in U.S. Adult health: the interplay of race and ethnicity. Social Science $\mathcal{E}$ Medicine, 62, 1045-1065.

Rogers, R. G., Hummer, R. A., \& Nam, C. B. (2000). Living and dying in the USA. New York: Academic Press.

Schulz, A. J., \& Mullings, L. (2006). Gender, race, class, and health: Intersectional approaches. San Francisco, CA: Jossey-Bass.

Shuey, K. M., \& Willson, A. E. (2008). Cumulative disadvantage and black-white disparities in life-course health trajectories. Research on Aging, 30(2), 200-225.

Singer, J. D., \& Willett, J. B. (2003). Applied longitudinal data analysis: Modeling change and event occurrence. New York: Oxford University Press.

Smith, J. P. (1999). Healthy bodies and thick wallets: the dual relation between health and economic status. Journal of Economic Perspectives, 13(2), 145-166.

Taylor, M. G. (2008). Timing, accumulation, and the black/white disability gap in later life: a test of weathering. Research on $\mathrm{Ag}$ ing, 30(2), 226-250.

Thornton Dill, B., \& Zambrana, R. E. (2009). Critical thinking about inequality: an emerging lense. In B. Thornton Dill, \& R. E. Zambrana (Eds.), Emerging intersections: Race, class, and gender in theory, policy, and practice (pp. 1-21). Piscataway, NJ: Rutgers University Press.

Verbrugge, L. M. (1989). The twain meet: empirical explanations of sex differences in health and mortality. Journal of Health and Social Behavior, 30, 272-304.

Verbrugge, L. M., \& Jette, A. M. (1994). The disablement process. Social Science \& Medicine, 38(1), 1-14.

Waite, L. J. (1995). Does marriage matter? Demography, 32, 483-507.

Warner, D. F., \& Hayward, M. D. (2006). Early life origins of the race gap in men's mortality. Journal of Health and Social Behavior, 47(3), 209-226.

Williams, D. R., \& Collins, C. (1995). U.S. Socioeconomic and racial differences in health: patterns and explanations. Annual Review of Sociology, 21, 349-386.

Williams, D. R., \& Wilson, C. M. (2001). Race, ethnicity, and aging. In R. K. Binstock, \& L. K. George (Eds.), Handbook of aging and the social sciences (5th ed.). (pp. 160-178) San Diego, CA: Academic Press.

Willson, A. E., Shuey, K. M., \& Elder, G. H., Jr. (2007). Cumulative advantage processes as mechanisms of inequality in life course health. American Journal of Sociology, 112(6), 1886-1924. 